\title{
Poverty, Food Programs, and Childhood Obesity
}

\author{
Sandra L. Hofferth \\ Sally Curtin
}

\begin{abstract}
Sixteen percent of children 6-11 years of age were classified as overweight in 1999-2002, four times the percentage in 1965. Although poverty has traditionally been associated with underweight as a result of poor diet, researchers have recently pointed to a paradox in the U.S., which is that low income and obesity can coexist in the same population. This paper first examines whether income is linked to overweight in school-age children. Second, it explores whether food programs such as the Food Stamp Program, the National School Lunch Program, and the School Breakfast Program are associated with overweight among children in different income groups. The data come from the nationally representative 1997 Panel Study of Income Dynamics Child Development Supplement. No evidence either that poor children are more likely to be overweight or that food programs contribute to overweight among poor children was found. () 2005 by the Association for Public Policy Analysis and Management
\end{abstract}

\section{INTRODUCTION}

The prevalence of overweight children in the United States has become an increasing public health concern. Sixteen percent of children 6-11 years of age were classified as overweight in 1999-2002, four times the percentage in 1965 (Hedley et al., 2004). Changes in diet and activity levels are contributing factors. Per capita food energy availability has increased by about 15\% since 1970 (Harnack, Jeffrey, \& Boutelle, 2000), whereas children's physical activity is believed to have declined (Centers for Disease Control and Prevention, 2003; Hofferth \& Sandberg, 2001). Although, in developing countries, low income has traditionally been associated with underweight as a result of poor diet (Pollitt et al., 1996), researchers have pointed to a paradox in the U.S., which is that low income and obesity can coexist in the same population (Alaimo, Olson, \& Frongillo, 2001). Editorials in major media outlets have pointed to the possibility that food programs may contribute to an epidemic of overweight by providing too much food or the wrong kind of food (Besharov, 2002). Whether and how food programs contribute to obesity among children would be helpful for federal and local administrators of food programs to

Manuscript received February 2004; review completed June 2004; revised manuscript submitted September 2004; revision review completed January 2005; revised manuscript submitted January 2005; accepted February 2005. 
understand. If the issue is not resolved, administrators will face increased scrutiny, budget pressure, and programmatic decisions without sufficient information on the accuracy of a link between food programs and obesity. This paper explores, first, the relationship between family income and overweight among a nationally representative sample of elementary-school age children, and, second, whether participation in food programs such as the Food Stamp Program, the National School Lunch Program, and the School Breakfast Program is associated with overweight among eligible children.

\section{OVERVIEW AND CONCEPTUAL MOTIVATION}

The incidence of hunger among children in the United States is low. Less than 1\% of children were identified as being food insecure with hunger in 2001 (Nord, Andrews, \& Carlson, 2002). A more prevalent problem is the uncertain ability to acquire acceptable food because of lack of money, known as food insecurity, which characterizes $17.6 \%$ of children's families. Low income is the major factor contributing to this condition (Hofferth, 2004). In 2001, 46\% of children in poor families and $37 \%$ of children with family incomes under $185 \%$ of the poverty line were food insecure, compared with $6 \%$ of children in families with incomes $185 \%$ of poverty and higher (Nord et al., 2002). Food insecure families also exhibited a much higher level of other types of hardships, such as borrowing money from friends and relatives, falling behind in paying bills, and postponing major purchases or medical care (Hofferth \& Ye, 2004). ${ }^{1}$

\section{Family Income and Obesity among Children}

Family income is a key factor in a family's ability to purchase desired foods and in food preferences. Research has consistently found an inverse relationship between income and obesity among adult women, but relatively little has focused on children, and the results of that research have not been consistent or strong (Sobal \& Stunkard, 1989). Two recent studies that have examined income and child overweight found an inverse relationship between income and overweight such that White girls from low-income (or low- and moderate-income) families were more likely to be overweight than those from high-income families (Alaimo et al., 2001; Kimm et al., 1996), and one of the studies found the same relationship for White boys (Alaimo et al., 2001).

Why would low-income children be more likely than high-income children to be overweight? A positive relationship between income and obesity is generally shown in developing nations, whereas a negative relationship appears in developed societies (Sobal \& Stunkard, 1989). High-income families have access to more consistent high-quality sources of food. Low income or insecure income may lead to the use of low-quality, high-fat food or to binge eating when food is available that can lead to obesity (Alaimo et al., 2001; Basiotis \& Lino, 2002; Wilde \& Ranney, 2000). Societal attitudes toward obesity may also explain this relationship. In many traditional societies, obesity is desirable because it indicates health and wealth (Sobal \& Stunkard, 1989). However, in developed nations, negative attitudes toward obesity

\footnotetext{
${ }^{1}$ This paper does not address the link between food insecurity and overweight. Although children whose families reported food insecurity with hunger had a higher incidence of overweight in simple tabulations, only 42 children were in such families. None of the preliminary analyses indicated a significant link between food insecurity or food insecurity with hunger and overweight status once other factors were controlled.
} 
are present at a very young age, and research suggests an increasing desire to be thin with increasing social class, particularly among girls (Dornbusch et al., 1984).

The negative linkage between income and obesity in developed nations provides our first hypothesis, that children from low-income families will be more likely to be overweight than those from high-income families. Income includes cash transfers, but not in-kind transfers such as from the Food Stamp Program and school food programs. The latter are estimated separately. Previous studies often referred to a broad group of low-income families with different resources in the category "low income" (such as under 185\% of poverty, under $130 \%$ of poverty, or under $\$ 10,000$ and $\$ 10,000$ to $\$ 19,999)$. This study contributes to the literature because it disaggregates poor from near-poor and working-class families to see whether the relationship is the same among these diverse groups relative to moderate-income and high-income families. Low income is also the major factor determining eligibility for food programs designed to reduce food insecurity and prevent hunger. It is important to take income into account when examining the effects of programs or we will falsely attribute effects to food programs that simply result from low income.

Five different food programs provide a secure source of food for children in lowincome families- the Food Stamp Program, the National School Lunch Program, the School Breakfast Program, the Summer Food Service Program, and the Child and Adult Care Food Program. This paper focuses on the first three, the Food Stamp Program, the National School Lunch Program, and the School Breakfast Program. Our data source did not collect information during the summer months so we have no information on participation in the Summer Food Service Program, and we focus on school-age children who are unlikely to be enrolled full-day in a child care program participating in the Child and Adult Care Food Program. The three programs we examine are the major sources of food supplements for lowincome school-age children.

The theoretical model is shown in Figure 1. Family characteristics and family income affect food consumed, which is measured by expenditures on food eaten at home, expenditures on food eaten out, the cash value of assistance from the Food Stamp Program, and lunches and breakfasts children eat at school. Food consumption, in turn, affects childhood weight, measured by body mass index (BMI), and

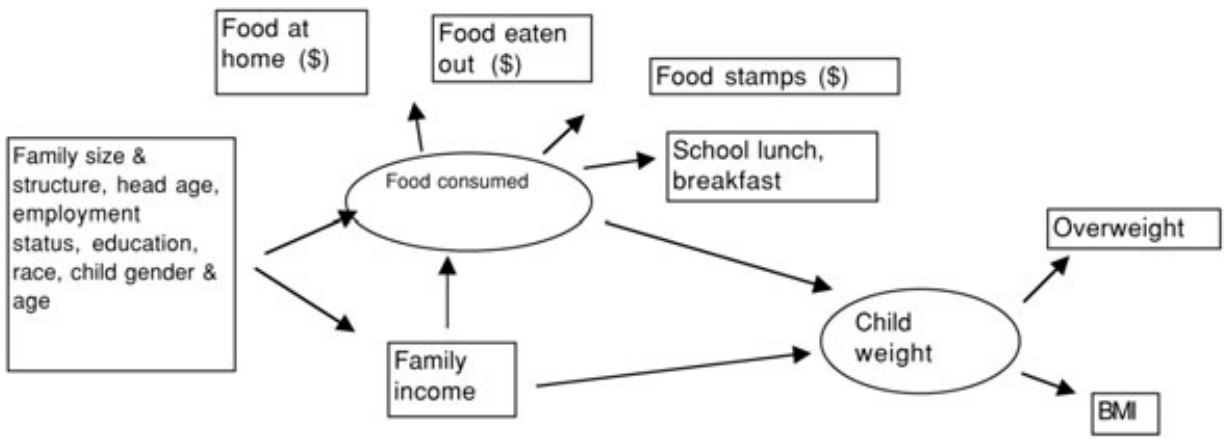

Figure 1. Relationships among income, food consumption, food programs, and child weight. 
overweight status. Although drawn in the model, whether income has any remaining effect on overweight after controlling for consumption is an empirical question.

\section{Expenditures on Food Prepared and Eaten at Home}

Income is typically used to indicate the material well-being of households; however, consumption may be a better measure (Meyer \& Sullivan, 2002). Income can be inaccurately measured; temporary fluctuations may lead to overstating or understating annual family income and cash or in-kind income may not be reported. The latter is a problem for measuring the actual resources of low-income families. Expenditures, such as those on housing and food, provide a more direct measure of material well-being. In the case of overweight, we examine expenditures on food, including the value of noncash food sources such as food stamps and at-home and away-from-home foods.

We hypothesize that the amount of food consumed, measured in dollars, will be linked to child overweight. Children in families who spend more money on food prepared at home (excluding Food Stamp Program benefits), net of family income, family size, and other characteristics, are expected to be more likely to be overweight. Of course, higher expenditures may reflect not only increased quantity but also increased quality, and awareness of quality tends to rise with income and education (Variyam, Blaylock, \& Smallwood, 1997). Offsetting a tendency to conserve funds by spending less on food, low-income households may actually be forced to pay more than moderate- or high-income households for food of equal quantity and quality. Low-income households face higher food prices in their neighborhoods because of the lack of high-volume supermarkets and lack of competition in lowincome areas (Kaufman, MacDonald, Lutz, \& Smallwood, 1997). Because of offsetting quality effects, the relationship between expenditures and overweight may be weak. No previous research has addressed this question.

\section{Expenditures on Food Eaten Out or Carried Home}

Research suggests that changes in children's diets between 1977 and 1995 have contributed to overweight. Primary school-age children (6-11) ate $32 \%$ of meals away from home in 1994-96, compared with $21 \%$ in 1977-78. For them, schools provide most of these away-from-home meals (43\%) followed by fast-food places $(30 \%)$, other places $(20 \%)$, and restaurants $(8 \%)$. The percentage of total caloric intake from fast foods more than quadrupled between 1977-1978 and 1994-1996, the largest increase of any category. Increased reliance on fast food and restaurants has increased children's intake of fat, saturated fat (Lin, Guthrie, \& Blaylock, 1996; Lin, Guthrie, \& Frazao, 1999; Lin, Guthrie, \& Frazao, 2001; Popkin, 2001), and calories (Bowman, Gortmaker, Ebbeling, Pereira, \& Ludwig, 2004). Thus, the proportion of income spent eating out or on carryout foods eaten at home is likely to be linked to overweight among children. Although fast-food consumption has been found to be positively associated with body mass index in adult females (Jeffrey \& French, 1998), we found no similar research on children. The present study provides some of the first evidence on this issue.

\section{The Food Stamp Program}

The Food Stamp Program (FSP) is designed to provide in-kind assistance so that a family can purchase a nutritionally adequate diet defined by a Thrifty Food Plan for 
a family of a given size. To be eligible for the FSP a family's gross income cannot exceed $130 \%$ of poverty and their net income (gross income minus a set of deductions, such as deductions for housing and employment expenses and for a share of earnings) cannot exceed the poverty line (Wilde, McNamara, \& Ranney, 2000). There is also a limit on assets other than a home, such as the value of a vehicle. As income rises, the amount of FSP benefits for which a family is eligible declines, therefore limiting the possibility of purchasing excess food. Food stamps are inkind benefits; only qualifying foods and non-alcoholic beverages can be purchased in participating retail stores. Restaurant meals are not included. Although a few states may still provide coupons, the program currently issues debit cards; recipients use the card to pay for eligible food items.

In order for the FSP to cause overweight among low-income children, the program would have to increase food intake substantially. This is because low-income children whose families do not participate in the FSP are more likely to be food insecure (Hofferth, 2004), which may lead to eating less than higher-income children and, therefore, a lower likelihood of being overweight. Research on the types of foods purchased and their dietary quality found that FSP program participants consume more meats, added sugars, and total fats than nonparticipants, although their consumption of other foods (fruits, vegetables, grains, and dairy) is the same (Wilde \& Ranney, 2000).

Does increased food consumption under the FSP lead to overweight? One study found the percentage of time in the Food Stamp Program over a five-year period to be linked to obesity in 5-11-year-old girls, even after adjusting for individual factors that affect both program participation and obesity (Gibson, 2004). However, the author was not able to explain why there would be an effect for this age group of girls when there was not a similar relationship for girls 12-17 or for either age group of boys, and why there was no effect on BMI. In addition, an earlier paper had found that Food Stamp Program participation was associated with a lower likelihood of low-income girls being overweight (Jones, Jahns, Laraia, \& Haughton, 2003). Although underweight is a possibility, some exploratory research by the present authors failed to identify evidence of systematic underweight of children from low-income families. Other research has also failed to find evidence that low income is associated with children being underweight (Korenman \& Miller, 1997). Additional exploration of the effect of the Food Stamp Program on child overweight is needed.

\section{The National School Lunch Program}

The National School Lunch Program (NSLP) provides meals to 25 million students each day (Food and Nutrition Service, 2004a). School lunches are expected to provide one-third of the recommended dietary allowances of protein, Vitamin A, Vitamin C, iron, calcium, and calories. Although the objective of the NSLP is to provide meals at reduced cost to children in families whose gross incomes are below 185\% of the poverty line, and free to those whose incomes are below $130 \%$ of the poverty line, higher-income students also benefit from the program. Only about half of school lunches are served to children from low-income families (Devaney, Ellwood, \& Love, 1997). Some children who are not eligible are approved for free or reducedprice meals and the remaining middle-class children who participate pay full price. Although the program increases nutrient intake, it has been criticized recently for providing lunches higher in fat than recommended (Burghardt, Devaney, \& Gordon, 1995). Compared with nonparticipants, children who participated in the NSLP 
ate a higher percentage of food energy from fat and saturated fat both during lunch and over a 24-hour period (Gordon, Devaney, \& Burghardt, 1995). Foods prepared at school are higher in fat, fiber, and calcium when compared with foods prepared at home (Lin et al., 1996). As a result, school food program participation could be linked to obesity in children, although no previous research has established a link. In response to this perceived problem, steps have been taken in recent years to enhance the nutritional quality of school meals, but little was in place at the time the present study was conducted (Lin et al., 1996).

The present study includes children participating in the school lunch or breakfast program regardless of whether they receive it free, for a reduced price, or pay "full price." ${ }^{2}$ What is important is that they eat a federally subsidized school lunch or breakfast. This is consistent with current research practice (Gleason \& Suitor, 2003). Because eligibility is determined on a six-month or annual basis, whereas income may change from month to month, some who are not technically eligible may receive subsidies. Eligibility for school food programs is parent-reported and verified on only a random sample of those participating. In addition, children from higher-income families can participate by paying for it. The fact that students of higher as well as lower income levels participate in the school lunch program helps us to disentangle income from food program effects on overweight.

\section{School Breakfast Program}

The School Breakfast Program (SBP) provides meals for 8.2 million eligible children in participating schools using the same eligibility criteria for free and reduced-price meals as the NSLP (Food and Nutrition Service, 2004b). School breakfasts must meet the same dietary guidelines (less than one-third of calories from fat) as do lunches but they are expected to provide only one-fourth of the recommended dietary allowance for protein, calcium, iron, Vitamin A, Vitamin C, and calories, compared to the one-third for lunches. SBP meals meet dietary recommendations for breakfast intake (Gordon et al., 1995). Although they have more protein than non-SBP breakfasts, they are equally or less dense in other nutrients. Thus, eating a breakfast at school is less likely to be linked to overweight than eating a hot lunch.

\section{Multiple Program Participation}

Given the similar eligibility criteria for these three programs (FSP, NSLP, and SBP), we might guess that children with family incomes under $130 \%$ of poverty would participate in all three and those with family incomes $130 \%$ of poverty or higher but under $185 \%$ of poverty would participate in the two school food programs. However, targeting is not perfect and not all children eat lunch at school. The School Breakfast Program is not as widespread as the National School Lunch Program, covering only about one-third the number of children. This variability also allows us to estimate the effect of the lunch versus the breakfast program. Rather than being a result of any one program, overweight may be the cumulative effect of multiple food program participation. If lunch provides one-third, breakfast one-quarter, and dinner provides another one-third of total calories, only a small allowance for

\footnotetext{
${ }^{2}$ Full-price lunches are federally subsidized, but the subsidy is small.
} 
snacks remains. Thus we expect the chance of being overweight to be greater for those eating both lunch and breakfast at school, compared with eating only lunch.

\section{Interaction between Income and Program Participation}

We anticipate that children from families who are not poor but just above the poverty line (near-poor and working-class) will have more access to food than children from poor families because of the former's greater economic resources and continued eligibility for food programs. The impact of having more income and access to food at home as well as more food at school through participation in the school lunch program could lead to a higher proportion of near-poor and workingclass children being overweight compared to either moderate-income or poor children. Thus we anticipate that eating a school lunch will be associated with a greater chance of being overweight for children in near-poor or working-class families than those in either poor or middle-class families. The single study examining multiple food programs and childhood obesity found a lower risk of overweight among lowincome school-aged girls who participated in food assistance programs (FSP, NSLP, and SBP) compared with those who did not participate (Jones et al., 2003). However, that study did not examine differences among income groups; only children from families with incomes below twice the poverty line were represented and subgroups were not examined. Nor did it examine BMI, which may have risen, but not by enough to result in being overweight.

\section{Confounding Factors}

A number of other factors may be linked to whether or not children are overweight, including age and sex of the child, race and ethnicity, education of parents, number and employment of parents, low birth weight, and family size (Kimm et al., 1996; Alaimo et al., 2001). Age and sex are inputs into determining whether a child is overweight; additionally, girls and boys may have differential tendencies toward overweight at different ages. Girls, for example, are more strongly influenced by the pressure toward thinness. Cultural factors may also be important. Families of different races/ethnicities may have different food preferences or attitudes toward obesity, and these may lead to greater or less risk of children being overweight. Bettereducated parents and those with smaller families may be more concerned about food quality than quantity and their children may have a lower risk of overweight as a result. Families with employed mothers or a single mother may spend less time on food preparation and depend on less nutritious meals, leading to greater chance of child overweight. Finally, children who start life low in birth weight may tend to remain that way (Stettler, Zemel, Kumanyika, \& Stallings, 2002). We adjust for these variables in multivariate analyses, using logistic regression for dichotomous "overweight" and ordinary least squares regression (OLS) for continuous BMI.

Unfortunately, we cannot control for all factors that may be associated with child overweight. If unobserved factors leading children to participate in the school food programs are also linked to being overweight, our estimates of their effects will be biased. Factors hypothesized to be associated with participation in the school lunch program include larger appetites and preferences for fattier foods or those providing more concentrated energy (Gordon et al., 1995). Recent research found that differences between NSLP program participants and non-participants in unobserved characteristics accounted for much of the significantly higher intakes of food energy, protein, thiamin, niacin, vitamin B-6, folate, iron, cholesterol, and sodium 
by NLSP participants compared with nonparticipants (Gordon et al., 1995). It is quite possible that this propensity for higher intakes of food energy among NSLP participants could lead to a higher BMI and propensity to be overweight among children. Consequently, this paper takes an instrumental variables approach in controlling for unobserved differences through modeling eating a school lunch and child overweight/BMI jointly.

\section{Hypotheses}

We hypothesize that children from low-income families will be more likely to be overweight and will have higher BMIs than those from high-income families. We also anticipate that higher food expenditures on food prepared at home or eaten out will be associated with a greater chance of child overweight. We hypothesize that the more money received in FSP benefits, the higher the BMI and the more likely children are to be overweight. Consistent with previous research showing an increase in nutrient intake among those participating, children eating a school lunch or eating a school breakfast are expected to have a higher BMI and to be more likely to be overweight than those not eating these meals at school with the same Food Stamp benefits and in the same income group. Finally, we expect that eating a school lunch or breakfast will increase the probability of overweight among children from near-poor and working-class families more than among children in poor families or moderate-income families.

\section{DATA AND METHODS}

\section{The 1997 Child Development Supplement}

Data for this study come from the 1997 Child Development Supplement (CDS) to the Panel Study of Income Dynamics (PSID), collected by the University of Michigan (Hofferth, Davis-Kean, Davis, \& Finkelstein, 1999). The PSID is a 30-year longitudinal survey of a representative sample of U.S. men, women, children, and the families in which they reside. In 1997, the PSID added a refresher sample of immigrants to the United States (since 1968) so that the sample represents the U.S. population in 1997. When weights are used, the PSID has been found to be representative of U.S. individuals and their families (Fitzgerald, Gottschalk, \& Moffitt, 1998a). With funding from the National Institute of Child Health and Human Development (NICHD), data were collected in 1997 on up to two randomly selected 0-12-year-old children of PSID respondents both from the primary caregivers and from the children themselves. The CDS survey period began in March 1997 and, with a break from mid-June through August, ended on December 6, 1997. Child interviews took place only during the school year. Interviews were completed with 2,380 households containing 3,563 children. The response rate was $90 \%$ for those families regularly interviewed in the core PSID and $84 \%$ for those contacted the first time that year for the immigrant refresher to the sample, yielding a combined response rate for both groups of $88 \%$. Post-stratification weights based upon the 1997 Current Population Survey are used to make the data nationally representative. The individual level child file used in this analysis is weighted by the product of the core PSID family weight, a post-stratification factor (by race and education of household head) based on comparison to the 1997 Current Population Survey, and a sub-selection weight that adjusts for the probability that a child in a given household was sampled and also for non-response of sampled children. All results presented are 
weighted, but the N's represent actual sample sizes. The sample used in this study consists of 1,449 school-age children age 6 through 12. There were 103 cases missing overweight; 55 cases missing head's education; 19 missing information on the NSLP, the SBP, or the FSP; and 4 missing family income. When these cases were deleted, the total sample size was 1,268 children. Because some of the children are siblings, analyses adjusted the standard errors for clustering within families and obtained robust standard errors using STATA.

\section{The National Health and Nutrition Examination Study}

The National Center for Health Statistics (NCHS) has conducted a series of health and nutrition surveys since the early 1960s, the National Health and Nutrition Examination Surveys (NHANES). The target population is the civilian noninstitutionalized U.S. population. Low-income persons, adolescents, persons 60 and over, African Americans, and Mexican Americans are oversampled but weights are provided to make the study nationally representative. In the most recent series of data collections (2001-2002), approximately 7,000 individuals were interviewed and about 5,000 of them completed a health examination component. The major advantage of this study is that height and weight of children are measured. The NHANES has several important limitations, however. First, even though it enrolls a large sample of individuals, only about 1,402 children 6-12 years of age participated in the examination component, compared with 1,449 in the PSID-CDS. In addition, income is less adequately measured in the NHANES than in the PSID. Public use data provide only categories of income. However, the NHANES has released the ratio of income to the poverty line for NHANES families, and that is the measure we use to compare with the CDS data. Most importantly, current NHANES data do not include information on participation in the food programs in which we are interested as well as on important control variables, though we understand these data will be released in future waves. For that reason, we use the NHANES as a comparison to see whether the income and overweight results are similar, then continue the analysis with only the PSID-CDS. If the overweight trends by income are generally consistent across the two data sets, we can have more confidence in the results from the CDS.

\section{Control Variables}

The demographic variables used in the PSID-CDS to analyze the impact of family factors on the overweight status of children 6-12 included race (non-Hispanic White, non-Hispanic Black, Hispanic, and other), age of head in 1997, age of child (ages $6-8=1,9-12=0)$, gender of child $(1=$ male, $0=$ female), and education of the head of household (less than high school, high school, at least some college, college or more). Race/ethnicity, age, education, and gender are likely to affect food preferences and knowledge about healthy eating. Whether the child weighed below 5.5 pounds at birth $(1=$ yes $)$, a marker for detrimental early environmental conditions, is expected to reduce the risk of overweight.

Employment and family structure place constraints on time that can be devoted to feeding the family. Family structure and the employment status of both parents were combined into a six-category variable - male breadwinner-female homemaker family; dual earner family; other two-parent (female breadwinner-male non-employed family or two-parent neither employed) family; single employed female head; single nonemployed female head; and single male-headed family. The male breadwinner-female 
homemaker category was the comparison/omitted category. Family size, measured by the number of children, provides an indicator of needed food resources.

The PSID calculates total annual household income from labor and nonlabor sources, including cash transfers but not including noncash benefits such as the FSP. The continuous income variable was never significantly linked to overweight among children. Because of our interest in potential interactions between income and child overweight, we created five income categories-poor (family income below $100 \%$ of the poverty line), near-poor (family income between 100 and $130 \%$ of the poverty line), working-class (family income between 130 and $185 \%$ of the poverty line, the upper limit in eligibility for the school lunch program), moderate-income (family income between 185 and 300\% of the poverty line), and high-income (family income $300 \%$ of the poverty line or higher).

PSID families were asked to estimate how much they spend on "food that you use at home" (not including food stamp dollars) and how much they spend "eating out, not counting meals at work or school" or on "food delivered to the door." Monthly dollar amounts were multiplied by 12 to provide a rough annual estimate of annual food expenditures in the same metric as annual family income. These numbers were then scaled to the same units as continuous total household income by dividing by 1,000 .

\section{Measuring Childhood Obesity and BMI}

The CDS asked primary caregivers to report their child's current weight. If they did not know their child's weight, they were asked to provide an estimate and they were asked when the child was last weighed. In the NHANES, children were weighed. The interviewer in both surveys measured the child's height. This information was used to compute a body mass index (BMI), calculated as weight in kilograms divided by the square of height in meters. The Centers for Disease Control and Prevention's (CDC) Year 2000 growth charts that show BMI-for-age were used to determine the threshold of overweight among children (Kuczmarski, Ogden, \& Guo, 2002). Although some studies have used the 85th percentile for age and sex, the group "at-risk for overweight," we used the standard definition of overweight, the 95th percentile (Hedley et al., 2004). That is, children whose BMIs were at or above the 95th percentile for their age and sex were classified as overweight. When the data were weighted by population weights, the prevalence of overweight in the CDS sample of 6-12-year-olds was $16.4 \%$, almost exactly the same as the $16.5 \%$ for children 6-11 in the 2001-2002 NHANES.

\section{Measuring Participation in Food Programs}

Because Food Stamp Program benefits decline with income, it is important to consider the cash value of the benefit participants receive. The PSID asks the amount of food stamps received monthly and number of months received. This was transformed into an annual measure for this analysis and scaled by dividing by 1,000.

Direct questions were asked of the child's primary caregiver about whether the target child "usually eats a complete hot lunch offered at school," whether the lunches were "full-price, reduced-price, or free," and whether the child "usually eats breakfast at the school under the Federal School Breakfast Program." Because the issue is the food eaten and not the amount of subsidy, we included all who said their child ate a complete hot lunch as "received lunch." Whether the child eats the hot lunch will be more relevant to overweight than the price paid for that lunch. 


\section{Analysis Plan}

In this paper we use two approaches to examine food program effects. First, we examine mean differences in the overweight status of children by categories of family income (poor, near-poor, working-class, moderate-income, high-income) using the NHANES and the PSID-CDS. Next, using the PSID-CDS, we examine children's mean proportion overweight and BMI by income and by participation in the FSP, the NSLP, and the SBP in the same five groups. This directly addresses the hypothesized linkage between poverty and child overweight and between program participation and overweight. By also examining differences in the BMI of children according to income and to program participation, the paper addresses the issue of how much poverty and food programs alter the weight of children adjusted for height. Programs could alter weight but not lead to large increases in the proportion of children overweight.

The second approach is to examine whether, net of other factors in a multivariate context, food programs are linked to childhood overweight and to BMI. Using the PSID-CDS, we first regress overweight and BMI on food programs and controls, using logistic regression and OLS. Second, we use instrumental variables to identify the impact of eating a school lunch on overweight and BMI. We do not use instrumental variables to identify the impact of the School Breakfast Program because too few children participate in that program and do not also eat a school lunch. Other research found no evidence of selection bias in participation in the SBP, whereas it did for the NSLP (Gordon et al., 1995). The following equations depict a model of child overweight/BMI that accounts for the school lunch participation decision:

$$
\begin{gathered}
Y=X_{i} \beta+P_{i} \delta+\varepsilon_{i} \\
\hat{P}_{i}=Z_{i} \lambda+u_{i}
\end{gathered}
$$

where $Y$ is overweight/BMI, $X$ is a set of observed exogenous variables that are associated with overweight/BMI, $P$ is the observed propensity to eat a school lunch, $P$ is the predicted probability of eating a school lunch, $Z$ is a set of variables affecting that probability, and $\varepsilon$ and $u$ are random disturbance terms.

We first regress whether the child eats a hot lunch at school on $Z$, the full set of exogenous variables $(X)$ plus an instrument (Equation 2). The instrument has to be a variable that is associated with participation in the school lunch program but is not associated with child overweight or BMI. One of the key factors associated with participation is attendance at a school that offers the program. Public schools are more likely to offer a subsidized hot lunch than are private schools, but, even so, students in both types of schools reported eating a hot lunch at school-71\% of children in public schools and $44 \%$ of children in private schools. In our analyses, we found a highly significant association between a dummy variable indicating that the child attends public school and eating a hot lunch at school. In contrast, public school attendance was not associated with the child's BMI or with the child's probability of being overweight. Because it is strongly associated with whether a child eats a hot lunch but is not associated with overweight or BMI, public school attendance serves as an excellent instrument to adjust for unobserved selectivity into the school lunch program in estimating the effects of eating a school lunch on overweight. In the second step, we obtain a predicted propensity to eat a school lunch, and that variable is substituted for the observed $P$ of Equation 1. 


\section{RESULTS}

\section{Sample Characteristics}

Table 1 shows average family income, food expenditures at home and away from home, Food Stamp Program benefits, and participation in school lunch and breakfast programs, by income categories. As expected, consumption of food at home and eaten out rises with income, and FSP benefits decline. There is a net gain of $\$ 1,323$ in total food expenditures between families who are poor and those who are near poor. This consists of an increase of $\$ 2,163$ in food expenditures at home and a doubling of money on food eaten out, from $\$ 567$ to $\$ 1,001$, offset by a decline of $\$ 1,274$ in Food Stamp benefits. From near-poor to working-class there is a net decline in food expenditures of $\$ 285$, consisting of a decline of $\$ 215$ in cash food expenditures, a small increase of $\$ 65$ in money spent eating out, and a decline in Food Stamp benefits of $\$ 135$. Between working-class and moderate-income, there is a net increase of food expenditures of $\$ 426$. This consists of an increase in food prepared at home of $\$ 830$, an increase in eating out of $\$ 111$, and a decline in Food Stamp Program dollars of $\$ 508$. From moderate- to high-income there is an increase of $\$ 762$, consisting of $\$ 456$ in increased food expenditures, $\$ 494$ in increased expenditures eating out, and a decline in Food Stamp benefits of $\$ 188$. When considering money spent on food prepared at home, the largest net increase in food expenditures occurs when families move from being poor to being nearpoor. The next-largest increase is moving from moderate- to high-income.

The lower panel shows participation in the school lunch and breakfast programs. Nine out of 10 poor and near-poor children eat a school lunch, and so do 8 of 10 working-class children. The National School Lunch Program benefits even moderate- and high-income children. Seven out of 10 children from moderate-income and 5 of 10 children from high-income families eat a hot lunch at school. School Breakfast Program coverage is much lower. Six of 10 children from poor families and half of children from near-poor families eat a breakfast at school, but that declines to $33 \%$ of working-class children, $19 \%$ of moderate-income, and only $6 \%$ of highincome children. Multiple program participation is common. Almost everyone who eats a school breakfast also eats a school lunch; the proportion eating a school breakfast is almost identical to the proportion eating both a lunch and breakfast. When we control for school breakfast and lunch in the same multivariate analysis, the coefficient for breakfast indicates the difference between those who eat a lunch only and those who also eat a breakfast. In our data, only 14 children ate a breakfast and did not eat a school lunch, too small a group to analyze separately.

\section{Poverty and Overweight}

Overall there is no linear association between the income to poverty ratio and overweight. The linear variable was never significantly associated with overweight or BMI (not shown). However, we hypothesized that the relationship might not be linear. Table 2 shows the proportion of school-age children who were overweight in the PSID-CDS and the NHANES, according to the ratio of the family's income to the poverty line, for all children and for children in five categories of income-poor, near-poor, working-class, moderate-income, and high-income.

In the PSID-CDS (top panel), 16.4\% of children 6-12 were overweight in 1997 and the average BMI was 18.4. The relationship between income and overweight is not linear. Children in families whose incomes ranged from $100 \%$ to $300 \%$ of poverty 


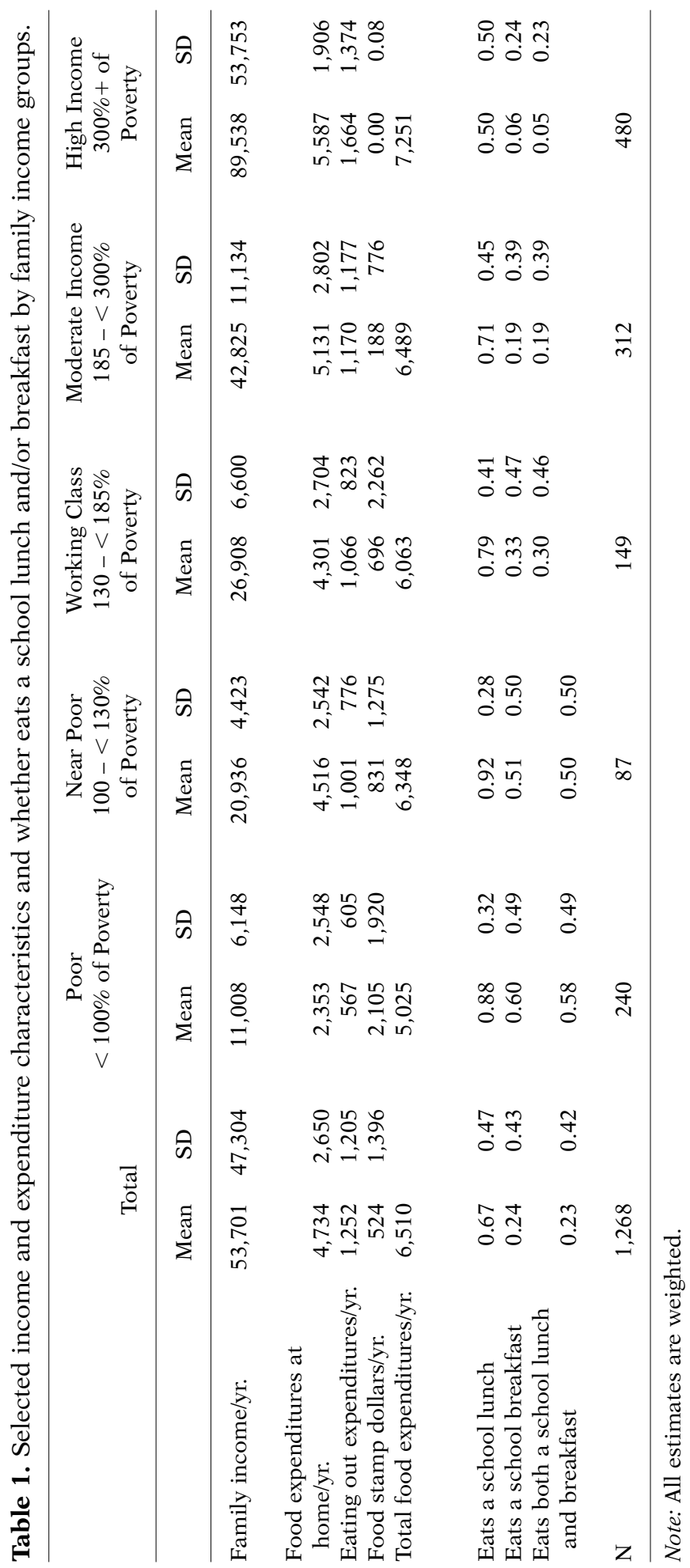




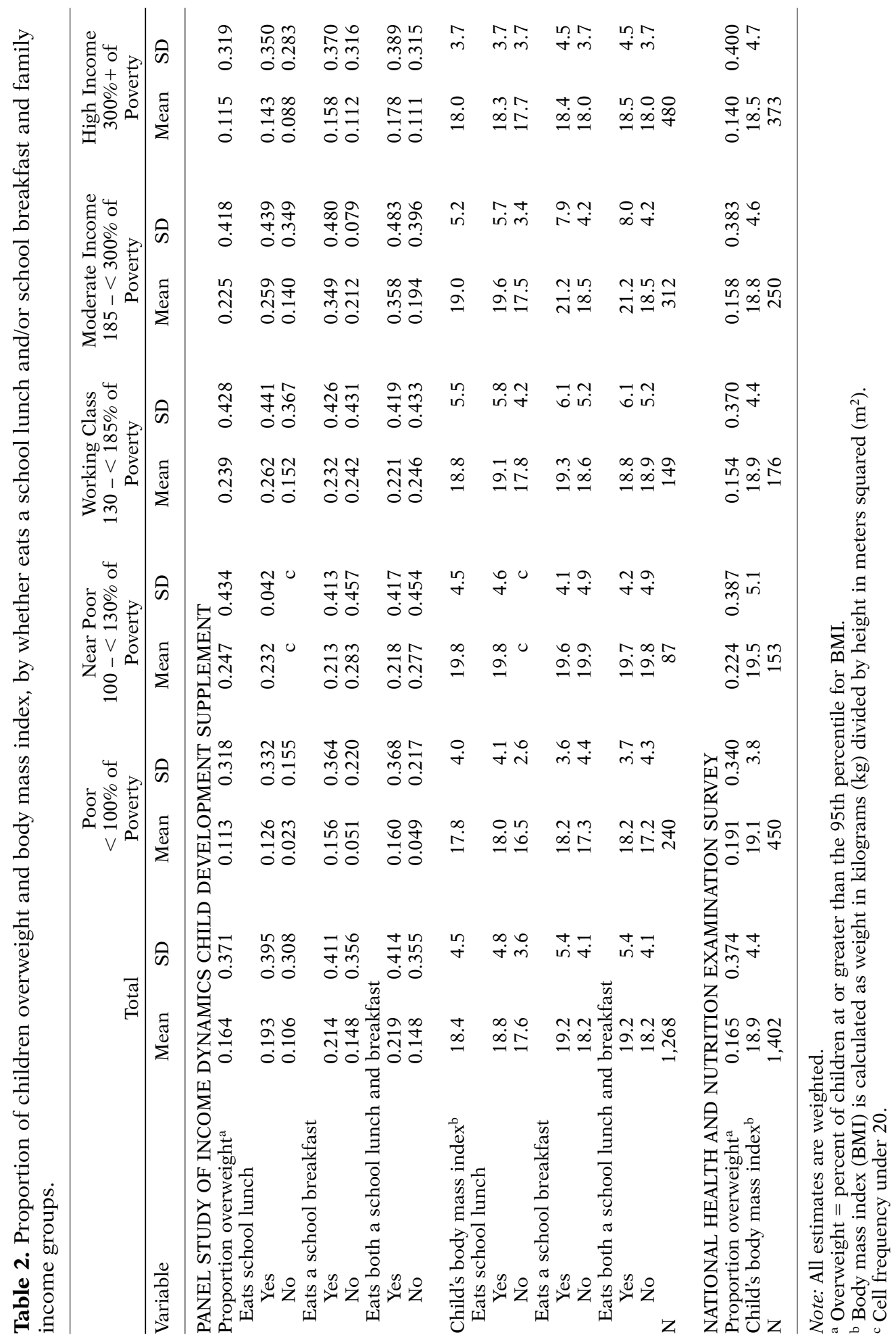


were more likely to be overweight (22-24\%) than children from families with incomes below $100 \%$ of the poverty line $(11.3 \%)$ or children in families with incomes of $300 \%$ of poverty or higher $(11.5 \%)$. The results for BMI are similar. The BMI for children in families with incomes between 100 and $300 \%$ of the poverty line is higher than for children in families with incomes below $100 \%$ or at or above $300 \%$ of poverty. These results do not support the hypothesis that low income and child overweight go together. Consistent with earlier research (Jones et al., 2003), they suggest that children in poor families are less likely to be overweight and have lower BMIs than most other children. They also suggest that children in families with incomes just over the poverty line are the ones at risk of being overweight and having the highest BMI.

The distributions from the NHANES 2001-2002 (lower panel) are strikingly similar. Overall, $16.5 \%$ of children 6-12 were overweight and the mean BMI was 18.9. The proportion overweight among children in poor families is higher in the NHANES than in the CDS. When we examined overweight and BMI from children below the poverty line, we found that $19 \%$ of children below $100 \%$ of poverty were overweight. This is still lower than the $22 \%$ of children with family incomes between $100 \%$ and $130 \%$ of poverty, though higher than the $14-15 \%$ of children with incomes of $130 \%$ poverty or higher. Additional analyses not shown here found that, in the NHANES, $11.5 \%$ of children in families with incomes below $50 \%$ of the poverty line were overweight, compared with $23.8 \%$ of children in families with incomes of 50 to $100 \%$ of the poverty line. Because the NHANES asked total family income in one question, whereas the PSID-CDS has measures of income components, it is not surprising that the income/overweight status relationship differs between the two samples. Previous research (Meyer \& Sullivan, 2002) has shown that low-income families underreport income. Errors in income reporting around the cut-offs could easily move a family from one category into the adjacent one. Adding unmeasured income received by low-income families would likely move some NHANES families a category higher. In any case, the overall conclusion that children in low-income families are not the most likely to be overweight holds. Instead, children in families that are just above the poverty line are more likely to be overweight. The association between income and overweight in the Early Childhood Longitudinal Survey, Kindergarten Cohort (ECLS-K), is similar to that obtained from the PSID-CDS. In the ECLS-K, $18 \%$ of children from families with incomes between 100 and $130 \%$ of the poverty line were overweight, in comparison to $15 \%$ of children whose family incomes were under the poverty line and $13 \%$ of children in families with incomes above $130 \%$ of poverty (Dunifon, 2004).

\section{School Food Programs and Child Overweight}

According to PSID-CDS data, in all income groups except the near-poor, children who eat a school lunch are more likely to be overweight and their BMIs are higher than those who do not. Except for the near-poor and working-class, the same holds for those who eat a breakfast. The difference in overweight between children eating a lunch and those who do not is equally large in the different income groups. For example, the difference between the proportion overweight for lunch eaters and non-lunch eaters in poor families is 10 percentage points, compared with 11 percentage points in the working class and 12 percentage points in moderate-income families. Similarly, the difference in BMI between children eating a school lunch and those not eating a lunch is 1.5 for children in poor families, 1.3 for children in working-class families, and 2.1 for children in moderate-income families. The 
results suggest that the relationship between program participation and overweight may not vary systematically by income group.

Table 2 shows considerable benefits of food programs to children from poor families. The BMI for all children is 18.4 , according to the PSID-CDS, and the BMI for all poor children is 17.8. The BMI of poor children who do not eat a school lunch (16.5) is 1.3 units below the average of all poor children and 1.9 units below the average of all children, while the BMI of poor children who eat a school lunch (18.0) or both a lunch and breakfast (18.2) is about average for all children. Thus, school food programs help children attain a weight for height that is average for their age group.

\section{Analysis of Participation in the NSLP}

Table 3 shows the results of regressing whether a child eats a school lunch, our measure of NSLP participation, on enrollment in a public school and other background variables. The model explains about $22 \%$ of the variance. Whether the child attends public school is significantly linked to eating a school lunch, with children enrolled in public school much more likely to eat a hot school lunch than those enrolled in private school. Children living in families that spend more on food eaten at home are less likely to eat a school lunch, even after controlling for income categories. Because of common program eligibility, eating a school breakfast is associated with eating a school lunch.

Black and Hispanic children are more likely than White children to eat a hot school lunch. Children with a parent who has completed less than high school are also more likely than children of better-educated parents to eat a hot school lunch. Finally, children living with two parents, of whom neither is employed or only the wife is employed, are more likely to eat a hot school lunch. All these factors suggest greater financial need. Finally, children 6-8 are less likely to eat a hot lunch than are children 9-12 years of age.

\section{Multivariate Analysis of Food Programs and Child Overweight}

The bivariate analyses of overweight and BMI did not control for other variables that may be linked both to overweight and to food program participation. Table 4 shows the results relating food expenditures and food programs to child BMI and overweight, controlling for background variables. In the first six columns we see the results for child overweight and in the second 6 columns the results for child BMI, with Columns 1 to 4 in each panel showing the logistic (overweight) or OLS (BMI) results and Columns 5 and 6 the instrumental variables (IV) results.

Food Expenditures and Family Income. Neither the dollar amount of food expenditures nor the amount of FSP income is linked to child overweight or BMI (Table 4). Dollars spent eating out are linked to the child's BMI in Models 1 and 2 at the 0.10 level. As predicted, the more money spent eating out, the higher the child's BMI. Income is linked significantly and nonlinearly to child overweight and BMI. The coefficients are negative for children in poor families (significant in five of the six specifications) and for high-income families (marginally significant in the IV specification for overweight), compared with those in moderate-income families.

School Lunch and Breakfast Programs. In Logistic Model 1 (Table 4), eating a school lunch is associated with a significantly higher probability of being overweight $(\mathrm{p}<0.10)$ and a significantly higher BMI $(\mathrm{p}<0.05)$. The coefficient for eating a school breakfast represents the difference between eating only a lunch and eating both lunch and breakfast. As we see, eating a breakfast as well as a lunch 
Table 3. Coefficients from logistic regression of whether eats a school lunch on family income and expenditures, with controls.

\begin{tabular}{|c|c|c|}
\hline \multirow[b]{2}{*}{ Variable } & \multicolumn{2}{|c|}{ Child Eats a School Lunch } \\
\hline & Coefficient & SE \\
\hline \multicolumn{3}{|l|}{ School type } \\
\hline Child attends public school & $0.65^{* * *}$ & 0.25 \\
\hline Child attends private school & omitted & \\
\hline \multicolumn{3}{|l|}{ Income and expenditures } \\
\hline Food expenditures at home/yr (in 1,000 s) & $-0.09 *$ & 0.04 \\
\hline Money spent eating out/yr (in 1,000 s) & 0.00 & 0.08 \\
\hline Food stamp dollars received/yr (in 1,000 s) & -0.11 & 0.10 \\
\hline Poor $(<100 \%$ poverty line $)$ & -0.07 & 0.41 \\
\hline Near poor $(100 \%-<130 \%$ poverty line $)$ & 0.82 & 0.59 \\
\hline Working class $(130 \%-<185 \%$ poverty line $)$ & 0.18 & 0.38 \\
\hline Moderate income $(185 \%-<300 \%$ poverty line $)$ & omitted & \\
\hline High income $(300 \%$ or higher poverty line) & -0.33 & 0.24 \\
\hline Eats a school breakfast & $1.72 * * *$ & 0.39 \\
\hline \multicolumn{3}{|l|}{ Demographic controls } \\
\hline White & omitted & \\
\hline Black & $1.08 * * *$ & 0.29 \\
\hline Hispanic & $0.82+$ & 0.47 \\
\hline Less than high school & omitted & \\
\hline High school & $-0.56+$ & 0.33 \\
\hline Some college & $-0.73^{*}$ & 0.34 \\
\hline College & $-0.99 * *$ & 0.34 \\
\hline Child's age $6-8$ & $-0.29+$ & 0.17 \\
\hline Child's age $9-12$ & omitted & \\
\hline Number of children & 0.14 & 0.12 \\
\hline Age of head of household & -0.02 & 0.01 \\
\hline Child is male & 0.24 & 0.17 \\
\hline Child is female & omitted & \\
\hline Child was low birthweight & 0.51 & 0.38 \\
\hline Child was not low birthweight & omitted & \\
\hline Two parents, male working & omitted & \\
\hline Two parents, both working & 0.23 & 0.23 \\
\hline Two parents, other & $1.36^{* *}$ & 0.50 \\
\hline Female head, working & 0.30 & 0.41 \\
\hline Female head, not working & 0.52 & 0.74 \\
\hline Male head, no wife & 0.69 & 0.61 \\
\hline Constant & 1.16 & 0.83 \\
\hline $\mathrm{R}$ - square & 0.22 & \\
\hline Log likelihood & -628 & \\
\hline $\mathrm{N}$ & 1268 & \\
\hline
\end{tabular}

Note: All estimates are weighted; robust standard errors are presented. $+\mathrm{p}<.10,{ }^{*} \mathrm{p}<.05,{ }^{* *} \mathrm{p}<.01,{ }^{* * *} \mathrm{p}<.001$.

does not significantly increase the probability of being overweight or increase the BMI over that for children who eat only a lunch. When we included separate terms for lunch only and for both lunch and breakfast (not shown), we confirmed that the coefficient for eating both lunch and breakfast was stronger than that for lunch only, but not strong enough to significantly increase the risk of overweight. 


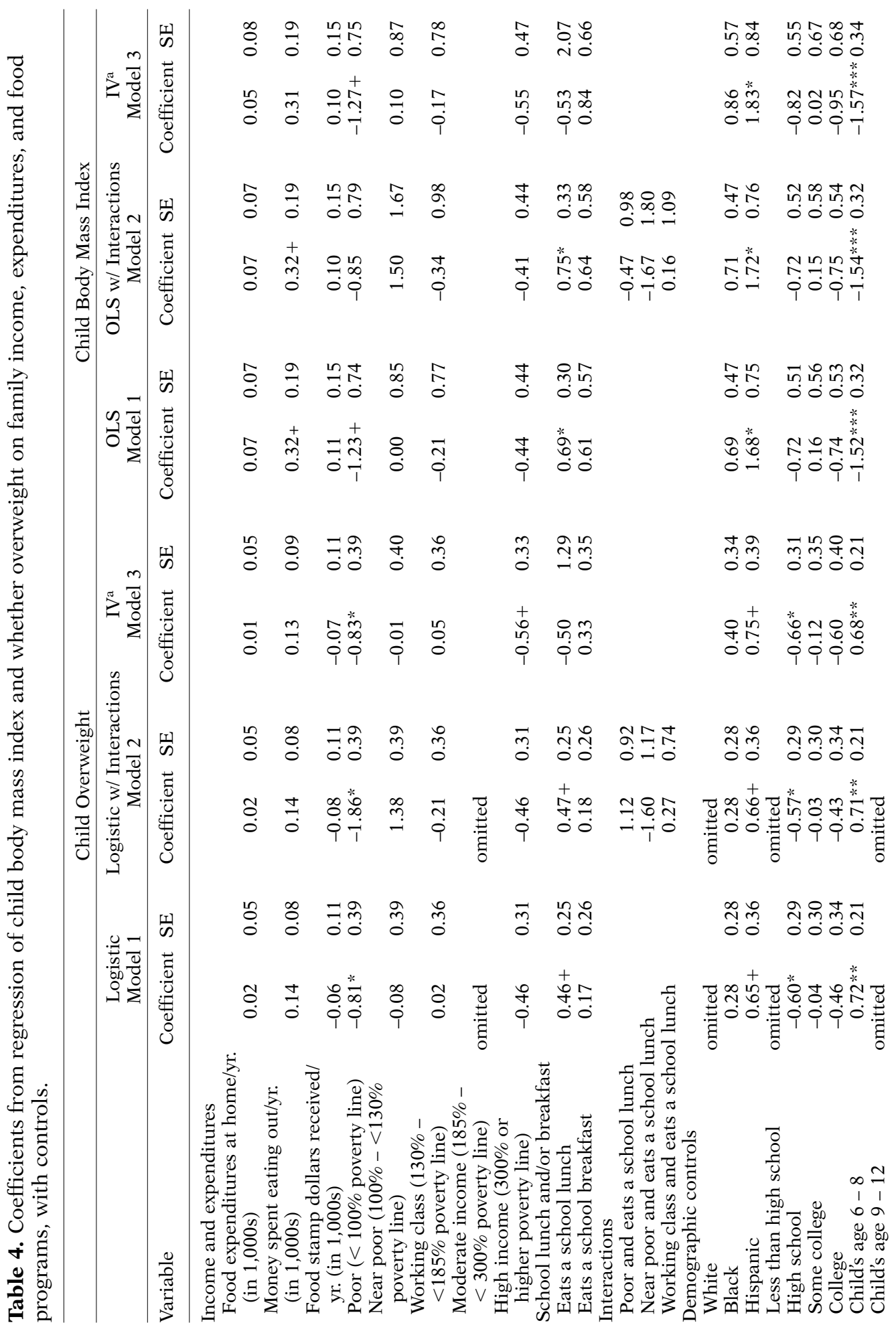




\begin{tabular}{|c|c|c|c|c|c|}
\hline 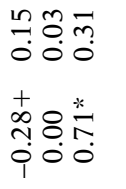 & $\begin{array}{l}\text { ñ } \\
0 \\
\text { nn } \\
\end{array}$ & & 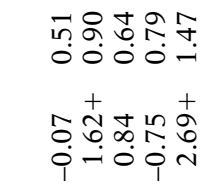 & 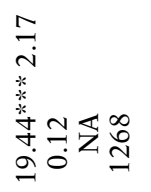 & \\
\hline 느 & in & & 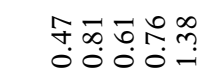 & $\stackrel{\text { f }}{-}$ & \\
\hline 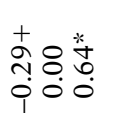 & $\stackrel{\sim}{\dddot{i}}$ & & 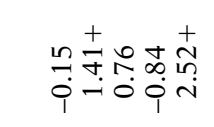 & 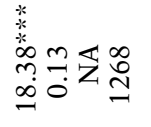 & \\
\hline ㄴ? & $\stackrel{n}{n}$ & & 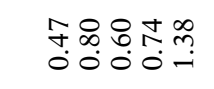 & $\stackrel{⿱ 乛 ⿻}{-}$ & \\
\hline 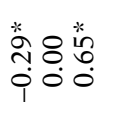 & $\stackrel{\mathscr{0}}{\dddot{1}}$ & & 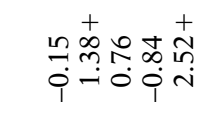 & 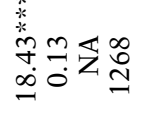 & \\
\hline 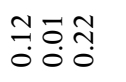 & $\stackrel{\infty}{\stackrel{\infty}{0}}$ & & 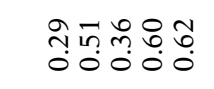 & $\stackrel{m}{m}$ & \\
\hline 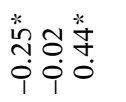 & $\stackrel{0}{0}$ & & 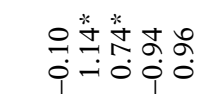 & 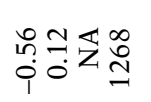 & \\
\hline 푸유. & $\stackrel{\infty}{m}$ & & 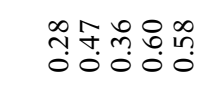 & $\begin{array}{l}\infty \\
\infty \\
0\end{array}$ & 章 \\
\hline 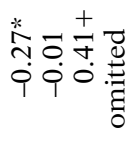 & $\frac{ \pm}{0}$ & 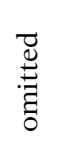 & 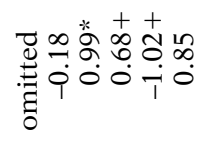 & 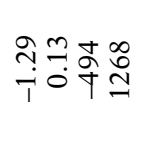 & 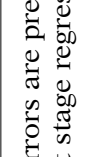 \\
\hline 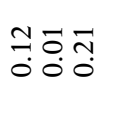 & $\stackrel{\infty}{m}$ & & 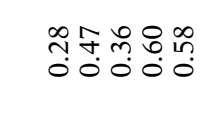 & $\begin{array}{l}\infty \\
\infty \\
0\end{array}$ & 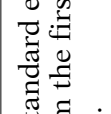 \\
\hline 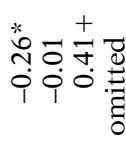 & $\begin{array}{l}n \\
0 \\
0 \\
0\end{array}$ & 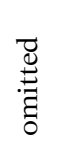 & 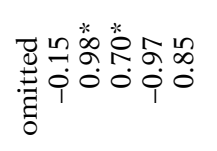 & 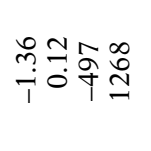 & 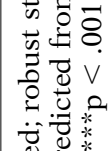 \\
\hline 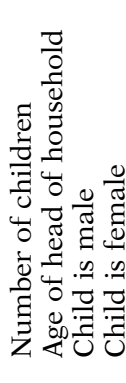 & 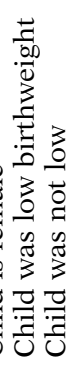 & 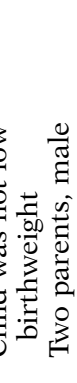 & 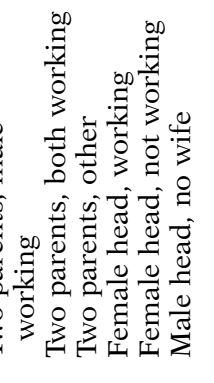 & 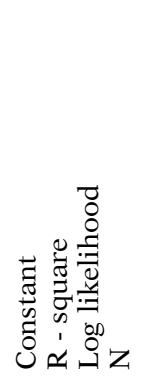 & 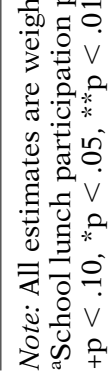 \\
\hline
\end{tabular}


In Logistic Model 2 we tested for an interaction between eating a school lunch and family income categories. We included interaction terms between eating a school lunch and dummy variables for children in families with incomes below poverty, for children in families with incomes between $100 \%$ and $130 \%$ of poverty (near-poor), and for children in families with incomes between 130\% and 185\% of poverty (working-class) to see whether the effects of eating a school lunch differed for these groups. Our hypothesis that near-poor and working-class children who ate a school lunch would be more likely than those who did not to be overweight or to have a higher BMI was not supported.

The IV estimate is shown in Model 3. The instrumental variables estimates show no significant effect of either eating a school lunch or eating a school breakfast on child overweight and BMI. This supports the argument that there are unobserved differences between children who participate and who do not participate in the school lunch program that lead to a greater likelihood of being overweight. This could be a preference for eating larger meals, for example, or for eating fattier foods, as suggested in earlier research on nutrients consumed by NSLP and SBP participants (Gordon et al., 1995). When such unobserved differences are removed, eating a school lunch is no longer associated with overweight and BMI.

\section{Control Variables}

As expected, there are differences in child overweight by race/ethnicity, probably reflecting different cultural preferences for food. Hispanic children are more likely to be overweight than White children. Younger children and children in small families are more likely to be overweight than older children and children in large families. Perhaps also a matter of parental feeding patterns and preferences, males are heavier in BMI and more likely to be overweight than females. Children of nonworking female heads or families in which the father is not working are less likely to be overweight, whereas children of working female heads are more likely to be overweight than children in two-parent, male earner families. Interestingly, children of male heads not living with a wife have a significantly higher BMI. Perhaps this is a result of using more prepared meals or of less attention to healthy meal preparation. Finally, children of high school graduates are less likely to be overweight than children of those who did not finish their high school degree. Although college education also has a negative coefficient, it is not significantly linked to overweight or BMI. The results do not support a strong education effect, net of other controls.

\section{DISCUSSION AND CONCLUSIONS}

This paper addressed two questions: (a) Is low family income associated with a greater likelihood of children being overweight? and (b) To what extent do food programs contribute to childhood overweight? With regard to the first question, the results are clear. Children from poor families are not more likely to be overweight than children from near-poor, working-class, or moderate-income families, but neither are children from families with high incomes. Instead, there appears to be a nonlinear association between child overweight/BMI and ratio of income to poverty. Children in poor and high-income families are less likely to be overweight whereas children in near-poor and working-class families are more likely to be overweight than those in moderate-income families. Because they failed to disaggregate the lowest income levels from those slightly higher, previous studies simply identi- 
fied the positive effect of living in a near-poor or working-class family on childhood overweight, but not the effect of living in a poor family.

Why is there a nonlinear relationship between income and child overweight? Based upon food expenditures, it appears that quantity increases with income up to a certain point, after which it most likely leads to higher quality rather than to a greater quantity of food. This would explain the paradox of a low proportion overweight at both the highest- and lowest-income levels. At the low level, there is a lower quantity of food and at the high level, greater quality. The near-poor, workingclass, and moderate-income groups may have both greater quantity and poorer quality of food. That this nonlinear relationship is still significant even after adjusting for food expenditures, food program participation, and demographic characteristics of the family suggests that greater income leads to purchasing higher quality. This could result from differential access to supermarkets or differential access to information about healthy eating habits in low- and high-income neighborhoods, factors not included in our models.

Second, participation in the Food Stamp Program is not associated with an increased chance of child overweight. Children in families receiving more Food Stamp Program benefits are neither more nor less likely than those who receive less to be overweight. Access to the FSP is also not the reason for the greater proportion of overweight among near-poor and working-class children. However, given the difference in findings among several previous studies, additional research needs to be conducted.

Third, participation in school food programs may be associated with a higher chance of being overweight. In our initial bivariate and multivariate analyses, children who ate a school lunch had a significantly higher BMI and a greater chance of being overweight than those who did not, and those who ate a lunch and breakfast also had a significantly higher BMI and chance of being overweight, though the breakfast itself did not increase risk significantly over just eating the lunch.

The BMI and overweight results are consistent with research showing that the school lunch provides a higher portion of children's food energy from fat $(38 \%)$ than recommended $(<$ or $=30 \%$ ) (Gordon et al., 1995). Because the lunch and breakfast together amount to at least $58 \%$ of children's daily calorie intake, this additional food may explain their greater chance of being overweight. More than half of students eat at least five times per day, thus consuming more than $100 \%$ of the recommended daily allowance (RDA) (Gordon et al., 1995). Non-NSLP lunches from home provide a much lower percent of the RDA than NSLP lunches whereas NSLP participants consumed $115 \%$ of the RDA over a 24 -hour period.

We explored the hypothesis that the effect of school food programs may be more salient for near-poor or working-class children. We saw in earlier analyses that nearpoor and working-class families spent more on food than poor families and were more likely to eat hot meals at school. Besides participation in the school food programs, children whose families are near poor or working class may also have more money to spend on competitive foods, that is, foods that are available in vending machines or the school snack bar, than do children in poor families. Thus, their children may be eating more food outside of the school lunch program. When we tested the hypothesis, however, we found no evidence of a more positive effect of eating a school lunch on the probability of being overweight and on BMI among near-poor or working-class children than moderate- income children.

An alternative explanation for the linkage between participation in food programs and overweight/BMI is selection. Research suggests that those who eat a school lunch (but not a school breakfast) differ from nonparticipants in being big eaters who would eat more anyway and be more likely to be overweight (Burghardt et al., 
1995; Moffitt, 1995). When we corrected for selection through an instrumental variables procedure, the association between eating a school lunch and overweight/BMI disappeared. This provides evidence of selectivity in who eats a lunch.

This study, therefore, ultimately failed to find either that low-income children are more likely to be overweight or that food programs contribute to overweight among such children when adjustment is made for other factors differentiating children and their families. On both counts speculation has been off the mark. First, the poorest children have significantly lower BMIs and risk of overweight than moderateincome children; near-poor, working-class, and moderate-income children have the highest BMIs and greatest risk of overweight. Second, poor children benefit from food programs. The BMI for poor children who do not eat a school lunch is below the average for all children in the study, whereas the BMI for children who eat the school lunch is about average. If food programs are linked to overweight, it is for children of near-poor and working-class families. For them, eating a school lunch is associated with a higher BMI and a greater chance of being overweight; however, this appears to result from a greater preference of children with a tendency to overweight to eat a hot school lunch. We recommend caution in interpreting this finding, however. If children with a tendency to be overweight are the ones who choose to eat a school lunch, a school lunch too high in fat and cholesterol could reinforce previous tendencies toward overweight. Therefore, this study should not be construed to argue that nutritional improvement in school meals is unimportant.

One limitation of the study is that the results do not take into account recent efforts by the USDA and states to improve the nutritional content of school meals. Whether the results would be the same if more recent data were available is unknown. Because food programs were not found to be causally linked to overweight in children, improvements in nutritional content would not be expected to reduce overweight and BMI among school-age children. However, such changes may help students at risk of overweight maintain a healthy weight.

\section{ACKNOWLEDGMENTS}

Funding for this research was provided by a grant from the National Institute of Child Health and Human Development to Sandra Hofferth, as a member of the Family and Child Wellbeing Research Network. Funding from the Economic Research Service, Food Assistance and Nutrition Research Program, USDA, was instrumental in getting this project started.

SANDRA L. HOFFERTH is Professor of Family Studies at the University of Maryland.

SALLY CURTIN is Faculty Research Assistant at the University of Maryland.

\section{REFERENCES}

Alaimo, K., Olson, C., \& Frongillo Jr., E. A. (2001). Food insufficiency and American schoolaged children's cognitive, academic, and psychosocial development. Pediatrics, 108(1), 44-53.

Basiotis, P. P., \& Lino, M. (2002). Food insufficiency and prevalence of overweight among adult women. Nutrition Insights, 26, 1-2.

Besharov, D. J. (2002, 8 December). We're feeding the poor as if they're starving [Editorial]. The Washington Post (Washington, DC), sec. Outlook, pp. B1, B5.

Bowman, S. A., Gortmaker, S. L., Ebbeling, C. B., Pereira, M. A., \& Ludwig, D. S. (2004). 
Effects of fast-food consumption on energy intake and diet quality among children in a national household survey. Pediatrics, 113(1), 112-118.

Burghardt, J. A., Devaney, B. L., \& Gordon, A. R. (1995). The School Nutrition Dietary Assessment Study: Summary and discussion. American Journal of Clinical Nutrition, 61(supplement), 252S-7S.

Centers for Disease Control and Prevention. (2003). Physical activity levels among children aged 9-13 years-United States, 2002. Morbidity and Mortality Weekly Report, 52(33), 785-788.

Devaney, B. L., Ellwood, M. R., \& Love, J. M. (1997). Programs that mitigate the effects of poverty on children. The Future of Children, 7(2), 88-112.

Dornbusch, S., Carlsmith, J., Duncan, P., Gross, R. M., Martin, J. A., Ritter, P., \& SiegalGorelick, B. (1984). Sexual maturation, social class and the desire to be thin among adolescent females. Journal of Developmental and Behavioral Pediatrics, 5, 308-314.

Dunifon, R. (2004, 13 July). Personal communication.

Fitzgerald, J., Gottschalk, P., \& Moffitt, R. (1998a). An analysis of sample attrition in panel data: The Michigan Panel Study of Income Dynamics. Journal of Human Resources, 33(2), 251-299.

Food and Nutrition Service. (2004a). National school lunch program. Retrieved September 24, 2004, from www.fns.usda.gov/cnd/lunch.

Food and Nutrition Service. (2004b). School Breakfast Program. Retrieved September 24, 2004, from www.fns.usda.gov/cnd/breakfast.

Gibson, D. (2004). Long-term Food Stamp Program participation is differentially related to overweight in young girls and boys. Journal of Nutrition, 134, 372-379.

Gleason, P. M., \& Suitor, C. W. (2003). Eating at school: How the National School Lunch Program affects children's diets. American Journal of Agricultural Economics, 85(4), 1047-1061.

Gordon, A., Devaney, B., \& Burghardt, J. (1995, January). Dietary effects of the National School Lunch Program and the School Breakfast Program. American Journal of Clinical Nutrition, 61(1 Suppl.), 221S-231S.

Harnack, L. J., Jeffrey, R. W., \& Boutelle, K. N. (2000). Temporal trends in energy intake in the United States: An ecologic perspective. American Journal of Clinical Nutrition, 71, $1478-1484$.

Hedley, A., Ogden, C., Johnson, C., Carroll, M., Curtin, L. R., \& Flegal, K. M. (2004). Prevalence of overweight and obesity among U.S. children, adolescents, and adults, 1999-2002. Journal of the American Medical Association, 291(23), 2847-2850.

Hofferth, S. (2004). Persistence and change in the food security of families with children (Food Assistance and Nutrition Research Report). Washington, DC: U.S. Department of Agriculture.

Hofferth, S., \& Sandberg, J. F. (2001). Changes in American children's time, 1981-1997. In S. L. Hofferth \& T. J. Owens (Eds.), Advances in life course research (vol. 6, pp. 193-229). Oxford, U.K: Elsevier Science.

Hofferth, S. L., \& Ye, H. Y. (2004). Why are some middle income families food insecure? Poster presented at annual meeting of the American Society for Nutritional Sciences, April 17-19, Washington, DC.

Hofferth, S., Davis-Kean, P., Davis, J., \& Finkelstein, J. (1999). 1997 user guide: The Child Development Supplement to the Panel Study of Income Dynamics. Ann Arbor, MI: Institute for Social Research, The University of Michigan.

Jeffrey, R. W., \& French, S. A. (1998, February). Epidemic Obesity in the United States: Are fast foods and television viewing contributing? American Journal of Public Health, 88(2), 277-280.

Jones, S. J., Jahns, L., Laraia, B. A., \& Haughton, B. (2003). Lower risk of overweight in 
school-aged food insecure girls who participate in food assistance. Archives of Pediatric and Adolescent Medicine, 157, 780-784.

Kaufman, P. R., MacDonald, J. M., Lutz, S. M., \& Smallwood, D. M. (1997). Do the poor pay more for food? (Agriculture Economic Report No. 759). Washington, DC: Economic Research Service, USDA.

Kimm, S., Obarzanek, E., Barton, B., Aston, C., Similo, S., Morrison, J., et al. (1996). Race, socioeconomic status, and obesity in 9- to 10-year-old girls: The NHLBI Growth and Health Study. Academy of Epidemiology and Pediatrics, 6(4), 266-275.

Korenman, S., \& Miller, J. (1997). Effects of long-term poverty on physical health of children in the National Longitudinal Survey of Youth. In G. Duncan \& J. Brooks-Gunn (Eds.), Consequences of growing up poor (pp. 70-99). New York: Russell Sage Foundation.

Kuczmarski, R., Ogden, C., \& Guo, S. (2002). 2000 CDC growth charts for the United States: Methods and development (Vital Health Stat No. 11[246]). Washington, DC: National Center for Health Statistics.

Lin, B.-H., Guthrie, J., \& Blaylock, J. R. (1996). The diets of America's children: Influences of dining out, household characteristics, and nutrition knowledge (Agricultural Economic Report No. 746). Washington, DC: U.S. Department of Agriculture.

Lin, B.-H., Guthrie, J., \& Frazao, E. (1999). Away-from-home foods increasingly important to quality of American diet (Agriculture Information Bulletin No. 749). Washington, DC: Economic Research Service, USDA.

Lin, B.-H., Guthrie, J., \& Frazao, E. (2001). American children's diets not making the grade. Food Review, 24(2), 8-17.

Meyer, B. D., \& Sullivan, J. X. (2002). Measuring the well-being of the poor using income and consumption. Focus, 22(2), 72-74.

Moffitt, R. (1995). Commentary on who participates in the National School Lunch Program and the School Breakfast Program. American Journal of Clinical Nutrition, 61, supplement, 250S-251S.

Nord, M., Andrews, M., \& Carlson, S. (2002). Household food security in the United States, 2001 (Food Assistance and Nutrition Research Report No. 29). Washington, DC: U.S. Department of Agriculture, Economic Research Service.

Pollitt, E., Golub, M., Gorman, K., Grantham-McGregor, S., Levitsky, D., Schurch, B., et al. (1996). A reconceptualization of the effects of undernutrition on children's biological, psychosocial, and behavioral development. Social Policy Report, X(5), 1-30.

Popkin, B. M. (2001). The nutrition transition and obesity in the developing world. Journal of Nutrition, 131(3) 871S-873S.

Sobal, J., \& Stunkard, A. J. (1989). Socioeconomic status and obesity: A review of the literature. Psychological Bulletin, 105(2), 260-275.

Stettler, N., Zemel, B., Kumanyika, S., \& Stallings, V. (2002). Infant weight gain and childhood overweight status in a multicenter, cohort study. Pediatrics, 109(2), 194-199.

Variyam, J. N., Blaylock, J., \& Smallwood, D. (1997). Diet-health information and nutrition: The intake of dietary fats and cholesterol (Technical Bulletin No. 1855). Washington, DC: Economic Research Service, USDA.

Wilde, P., \& Ranney, C. (2000). The monthly food stamp cycle: Shopping frequency and food intake decisions in an endogenous switching regression framework. American Journal of Agricultural Economics, 82, 200-213.

Wilde, P. E., McNamara, P. E., \& Ranney, C. K. (2000). The effect on dietary quality of participation in the Food Stamp and WIC programs (Food Assistance and Nutrition Research Report No. 9). Washington, DC: U.S. Department of Agriculture. 